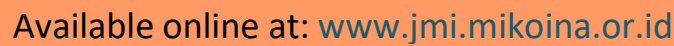 Jurnal Mikologi Indonesia

\section{Trichaleurina javanica from West Java}

\section{Rudy Hermawan ${ }^{1}$, Mega Putri Amelya ${ }^{1}, Z^{\prime}{ }^{\prime A z i z a}$ Ridha Julia ${ }^{1}$}

${ }^{1}$ Department of Biology, Faculty of Mathematics and Natural Sciences, IPB University, Dramaga Campus, Bogor 16680, Indonesia.

Hermawan R, Amelya MP, Julia ZR. 2020 - Trichaleurina javanica from West Java. Jurnal Mikologi Indonesia 4(2), 175-181. doi:10.46638/jmi.v4i2.85

\begin{abstract}
Trichaleurina is a fleshy mushroom with goblet-shaped within Pezizales. Many genera have a morphology similar to Trichaleurina, such as Bulgaria and Galiella. Some previous reports had been described fungi like Trichaleurina as Sarcosoma. Indonesia has been reported that has Trichaleurina specimen (the new name of Sarcosoma) by Boedijn. This research aimed to obtain, characterize, and determine the Trichaleurina around IPB University. Field exploration for fungal samples was used in the Landscape Arboretum of IPB University. Ascomata of Trichaleurina were collected, observed, and preserved using FAA. The specimen was deposited into Herbarium Bogoriense with collection code BO 24420. The molecular phylogenetic tree using RAxML was used to identify the species of the specimen. Morphological data were used to support the species name of the specimen. Specimen BO 24420 was identified as Tricahleurina javanica with $81 \%$ bootstrap value. Molecular identification was supported by the morphological data, such as the two oil globules and the size of mature ascospores.
\end{abstract}

Keywords - goblet-shaped fungi - Herbarium Bogoriense - Pyronemataceae

\section{Introduction}

Trichaleurina is a genus built by Rehm (1903) and known by other researchers since a publication of a valid genus by Rehm (1914). The genus is classified as Pezizales (Mycobank, 2020). According to Kirk (2008), Pezizales contains 199 genera and 1683 species. Trichaleurina has four species, i.e., T. celebica, T. javanica, T. polytricha, and T. tenuispora (Index Fungorum, 2020). Despite Index Fungorum (2020) recorded four species, the last publication (Carbone et al., 2013) mentioned only two species in their phylogenetic tree based on the molecular study.

Trichaleurina is included in Pyronemataceae (Rhem, 1903). The genus is not popular to study in this era, compared with the Bulgaria and Galiella as the same Pyronemataceae. Perry et al. (2007) had been studied the phylogenetics of the family Pyronemataceae, but they did not mention Trichaleurina in their phylogenetic tree. The knowledge of Trichaleurina is not often mentioned compared with other genera that have similar characters of morphology, i.e., Bulgaria, Galiella, and Sarcosoma. Trichaleurina had been reported for distribution in India (Patel et al., 2018). Specifically, the study mentioned T. javanica. The exploration of the genera happened in Indonesia (Boedijn, 1932), i.e., Sarcosoma orientale noted as a Java

Dikirimkan 28 Juli 2020, Diterima 1 November 2020, Terbit online 15 Desember 2020

Corresponding Author: Rudy Hermawan, e-mail: hermawan_rudy@apps.ipb.ac.id 
collection. Then, Carbone \& Agnello (2015) suggested the name becomes Galiella based on their herbarium analyses.

Among Bulgaria, Galiella, and Trichaleurina, the morphology of apothecium is similar. They have differences in the ornamentation and the spore, especially of their molecular. Carbone et al. (2013) studied and explained more about Bulgaria, Sarcosoma, and Trichaleurina. To distinguish the differences among the genera, a molecular study is needed to solve this problem.

\section{Materials and Methods \\ Fungal Sampling}

The apothecia were explored in January 2020 and located in the Arboretum of IPB University. The exploration was focused on the goblet mushroom for Trichaleurina. The apothecia were collected, documented, and observed the morphological characters. The observation was conducted in the mycology laboratory of Biology Department, Mathematics and Natural Sciences, IPB University, Indonesia. The apothecium was preserved in FAA (Kottapalli et al., 2016) and deposited into Herbarium Bogoriense, LIPI, Indonesia.

\section{Morphological Observation}

The morphological data of apothecia were observed and documented to confirm the species and support the molecular analyses. The observation was conducted using an Olympus stereo and binocular microscope cs22LED. The features of macro- and micromorphology such as excipular cells, paraphyses, asci, and ascospores. The observations were about the shape, size, and ornamentation, then compared with the other publication of the species within Trichaleurina.

\section{Molecular Identification}

The apothecia were identified using molecular analyses. The sterile part of apothecium was extracted to get genomic DNA. $500 \mu \mathrm{L}$ CTAB-buffer (cetyl-trimethyl ammonium bromide) was added into apothecium paste and incubated at $65^{\circ} \mathrm{C}$ for $30 \mathrm{~min}$. Then, $500 \mu \mathrm{L}$ of chloroform isoamyl alcohol (24:1) was added and centrifuged at 12,000 rpm for $15 \mathrm{~min}$. The supernatant was collected. $500 \mu \mathrm{L}$ of phenol: chloroform: isoamyl alcohol (25:24:1) was added and centrifuged at $12,000 \mathrm{rpm}$ for $10 \mathrm{~min}$. The supernatant was collected, and $50 \mu \mathrm{L}$ $2 \mathrm{M} \mathrm{NaOAc}$ (Sodium Hypo-Acetate) and $500 \mu \mathrm{L}$ absolute ethanol were added. This mixture was stored at $-20^{\circ} \mathrm{C}$ overnight, then centrifuged at $15,000 \mathrm{rpm}$ for $30 \mathrm{~min}$. The supernatant was removed. $300 \mu \mathrm{L}$ of $70 \%$ ethanol was added and centrifuged at 10,000 rpm for $5 \mathrm{~min}$. The supernatant was removed, and the DNA sample was in the pellet. The pellet was airdried using a Speed Vacuum on $30^{\circ} \mathrm{C}$ for $30 \mathrm{~min}$. The pellet was re-suspended in $50 \mu \mathrm{L}$ of TE-buffer and $10 \mu \mathrm{L} 1 \mathrm{mg} / \mathrm{mL}$ of RNAse. Then, the sample was incubated at $37^{\circ} \mathrm{C}$ for 10 min. RNAse was then deactivated by incubating the mixture at $70^{\circ} \mathrm{C}$ for $10 \mathrm{~min}$. DNA quality and quantity were verified using a nanodrop spectrophotometer.

The amplification was used Large Subunit (LSU) as forward LR0R (5'-GTA CCC GCT GAA CTT AAG C-3') and reverse LR5 (5'-ATC CTG AGG GAA ACT TC-3') primers. PCR amplification was performed in $40 \mu \mathrm{L}$ total reaction containing $12 \mu \mathrm{L}$ ddH2O, $2 \mu \mathrm{L}$ of 10 pmol of each primer, $20 \mu \mathrm{L}$ PCR mix from $2 \mathrm{X}$ Kappa Fast 2G, and $4 \mu \mathrm{L} 100 \mathrm{ng}$ template DNA. Amplification used a Thermoline PCR. The PCR condition was set as follows: initial denaturation at $94^{\circ} \mathrm{C}$ for 2 minutes, followed by 30 cycles of denaturation at $94^{\circ} \mathrm{C}$ for 45 seconds, annealing at $55^{\circ} \mathrm{C}$ for 1 minute, and extension at $72^{\circ} \mathrm{C}$ for 1 minute. Then final extension was set at $72^{\circ} \mathrm{C}$ for 10 minutes. The amplicons were estimated on $1 \%$ agarose gels and visualized by the Gel DocTM XR system. PCR products were sent to the $1^{\text {st }}$ Base Malaysia for sequencing. 


\section{Phylogenetic Analyses}

The sequence was deposited in GenBank. This sequence, 7 sequences of T. tenuispora, 3 sequences of T. javanica, 3 sequences of Galiella, 4 sequences of Bulgaria, and Geastrum saccatum (outgroup) were used for phylogenetic tree reconstruction (Table 1). Sequences were aligned using Clustal X Ver. 2.1 software and saved as PHYLIP format files. The phylogenetic tree of Randomized Axelerated Maximum Likelihood (RAxML) Black Box was generated on CIPRES (Stamatakis, 2014). Bootstrap analyses with 1000 replicates assessed the phylogenetic tree. Bootstrap (BS) $\geq 50$ was shown on the branch.

Table 1. The taxa used in this study

\begin{tabular}{llc}
\hline & & \\
Collection code & Species & GenBank acc. no \\
\cline { 2 - 3 } Voucher TNM F10376 TYPE & Trichaleurina tenuispora & NG_059958 \\
Voucher TNM F17974 & Trichaleurina tenuispora & KF418261 \\
Voucher TNM F4705 & Trichaleurina tenuispora & KF418258 \\
Voucher 420526MF0708 & Trichaleurina tenuispora & MH668019 \\
Voucher 420526MF0945 & Trichaleurina tenuispora & MH668020 \\
Voucher TNS F 31213 & Trichaleurina tenuispora & KF418265 \\
Voucher TNM F17898 & Trichaleurina tenuispora & KF418260 \\
Isolate HK022 Voucher HKAS 88981 & Trichaleurina javanica & MG871326 \\
Voucher TNM F8917 & Trichaleurina javanica & KF418266 \\
Voucher TUR A 198583 & Trichaleurina javanica & KF418269 \\
Voucher BO 24420 & Trichaleurina javanica & MT732395 \\
Strain WZ0111 & Galiella amurensis & AY789267 \\
AFTOL ID 129 & Galiella rufa & FJ176869 \\
CBS 912.72 & Galiella rufa & MH878298 \\
AFTOLN ID 916 & Bulgaria inquinans & DQ470960 \\
CBS 118.31 & Bulgaria inquinans & MH866601 \\
CBS 145.55 & Bulgaria inquinans & MH868960 \\
CBS 315.71 & Bulgaria inquinans & MH877810 \\
CBS 223.49 & Geastrum saccatum & MH868038 \\
\hline
\end{tabular}

\section{Results}

\section{Specimen description:}

Saprobic on the rotten wood (Figure 1a). Sexual morphology: Apothecium looks like globet- or cup-shaped (Figure 1b). The immature apothecium is more or less cylindric; wrinkled on the upper part; very dark grayish cyan of skin of apothecium; and hairy. The mature apothecium is exactly goblet-shaped with very dark grayish cyan on the surface; hairy; upper part of apothecium concave with soft orange; inside of apothecium fleshy gelatinousrubbery and tough (Figure 1c); $2.3-3.0 \mathrm{~cm}$ in diameter; $3.2-3.6 \mathrm{~cm}$ in height. The hair 25-100 $\times 5-10 \mu \mathrm{m}$, brownish cylindrical cell, rough surface's cell, septate cell, and apically blunt (Fig 1d). Paraphyses hyphae $490 \mu \mathrm{m}$ in length, septate, filiform, longer than ascus (Figure 1e). Excipular cells crowded, septate (Figure 1f). Asci 8-spored, long tapering base, cylindrical, 400-420 × 12-18 $\mu \mathrm{m}$ (Figure 1g). Ascospore ellipsoid or occasionally nearly subfusiform, mostly 2-4 oil globules inside, 18-31 × 15-17 $\mu \mathrm{m}$. (Figure 1h). Asexual morphology: Undetermined.

Specimen examined: Landscape Arboretum of IPB University, BO 24420, Rudy Hermawan, and Mega Putri Amelya. GenBank Submission: LSU: MT732395. Molecular work. The phylogenetic tree showed that the specimen BO 24420 was classified as T. javanica with $81 \%$ bootstrap value (Figure 2). Among Trichaleurina, Bulgaria, and Galiella were separated. 


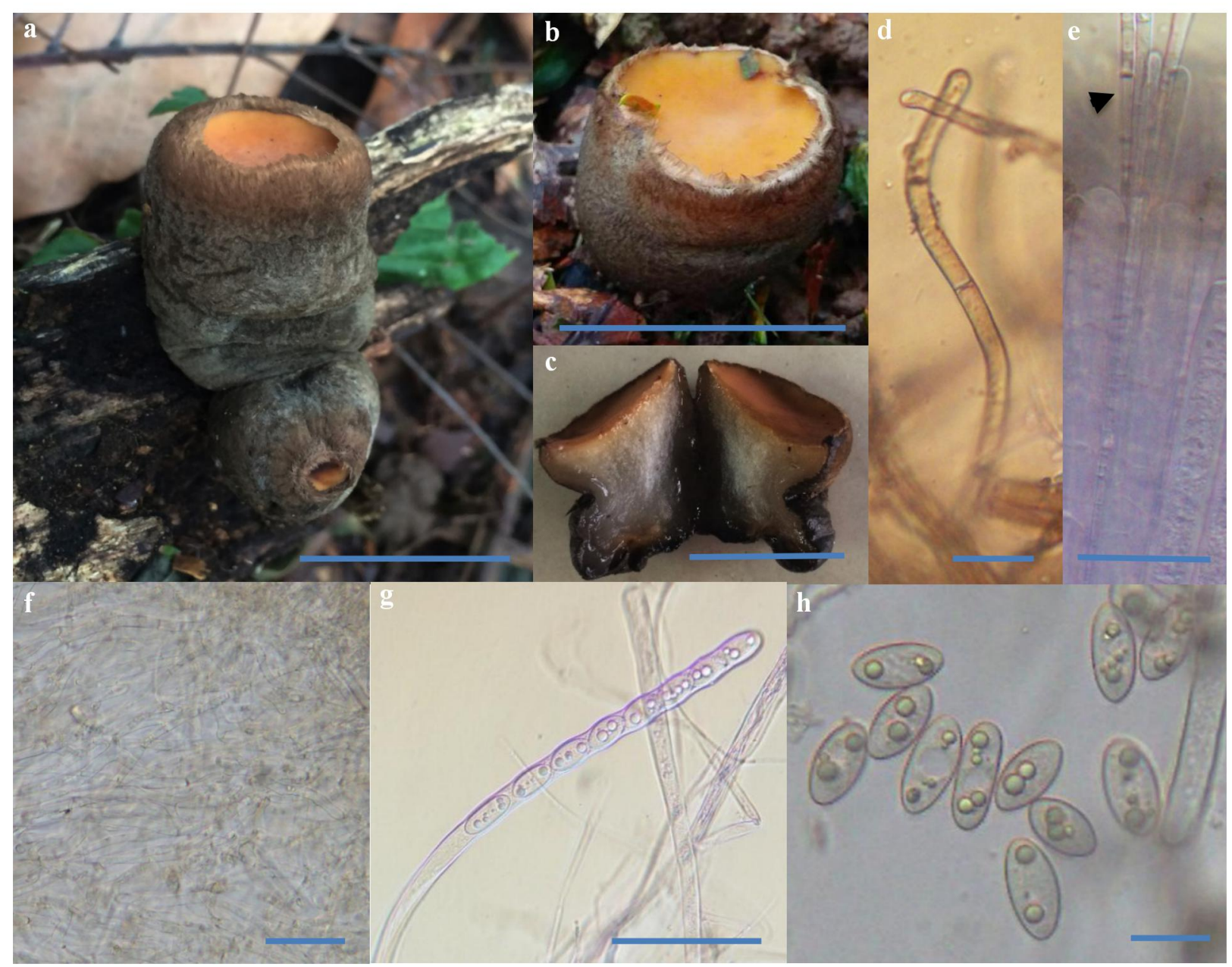

Figure 1. Morphology of Trichaleurina javanica. (a-b) apothecia on substrate; (c) slicing of apothecia; (d) cylindrical hair; (e) apically swollen paraphyses; (f) excipular cells; (g) asci; (h) ascospores. Scale bars: (a-c) $3 \mathrm{~cm}$; (d-f) $50 \mu \mathrm{m}$; (g) $100 \mu \mathrm{m}$; and (h) $30 \mu \mathrm{m}$.

\section{Discussion}

Trichaleurina has been reported for India's distribution (Patel et al., 2018), whereas Indonesia has not been reported yet. But the other genus with similar morphology, namely Galiella, has been reported for G. celebica in Saktu Island, Kepulauan Seribu, North Jakarta (Noverita et al., 2018). The identification was based on the morphology of apothecium. Trichaleurina javanica has a synonym by Galiella javanica (Mycobank, 2020). According to both morphologies, they have similar of apothecium seems like goblet-shaped. Another genus that has the similar morphology of apothecia as Trichaleurina is Bulgaria. The similar apothecia of them make a worried if the identification is only based on the morphology. The case had happened when some apothecia seem like goblet-shaped had been found in Indonesia by Boedijn (1932).

Further study corrects the specimens (Carbone et al., 2013). The apothecia found in the same place have two different genera, i.e., Bulgaria and Trichaleurina. Carbone et al. (2013) mentioned that the other specimens were based on the mature spore size. Identification of the goblet-shaped mushroom such as Bulgaria, Galiella, and Trichaleurina should be supported by the molecular study or specifically intensive morphology. 


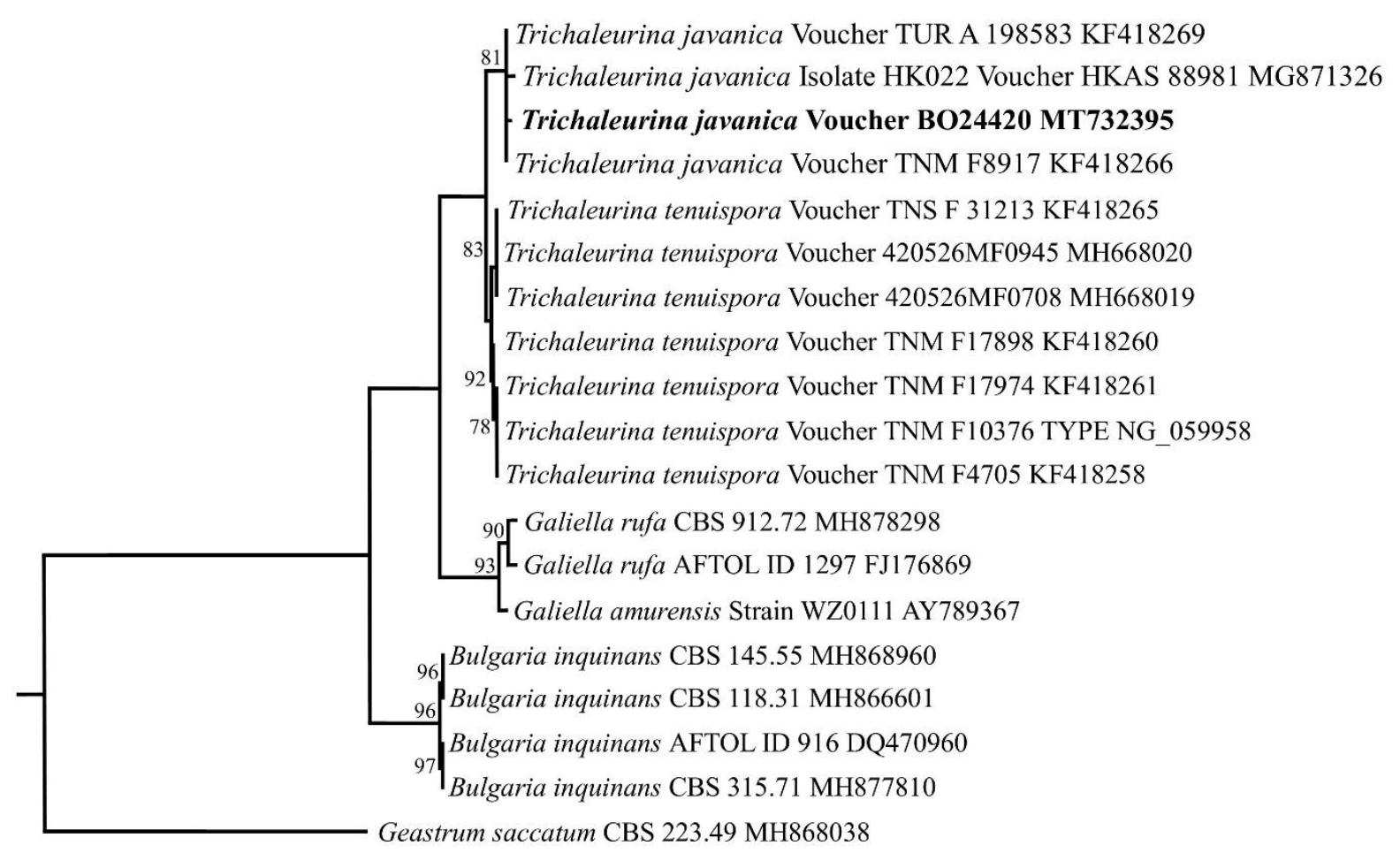

Figure 2. Trichaleurina javanica phylogenetic tree based on the LR0R/LR5 region using RAxML. Bootstrap (BS) $\geq 50$ was shown on the branch. The BO 24420 must be in bold.

According to the last publication about their molecular study, Trichaleurina has two species, i.e., T. javanica and T. tenuispora. The microscopic morphology that important to identify Trichaleurina in species is mature ascospores. T. javanica has $18-31 \times 15-17 \mu \mathrm{m}$, whereas T. tenuispora has $27-40 \times 12-15 \mu \mathrm{m}$. The size of T. tenuispora in size is bigger than $T$. javanica. Additionally, the inside appearance of ascospores among them is distinctly different. T. javanica has mostly two oil globules, whereas $T$. tenuispora has up to four mostly. The characters of T. tenuispora are cited in Carbone et al. (2013).

Trichaleurina is classified in Pezizales. The specific character is the operculate ascus, which is generally opened by rupturing to form a terminal or operculum (Hansen \& Pfister, 2006). Then, it is classified into Pyronemataceae. Pyronemataceae is a family that was built by Corda in 1842 (Index Fungorum, 2020). Based on Hansen \& Pfister (2006), this family is not monophyletic on their phylogenetic tree using the Neighbour Joining method. The phylogenetic tree was using a large combined small subunit to the identification. Other families are bore in the clade, i.e., Ascodesmidaceae and Glaziellaceae. The member of this family is changed along with the latest research published. Rifai (1968) mentioned only a single genus in this family, namely Pyronema. The character in this family is described by Apothecia minute, orange to red, ivory, scattered to gregarious, at first conical-shaped of apothecium, expanding to turbinate, with or without delicate hairs on the operculum part, asci operculate, 8-spored and paraphyses filiform (Rifai, 1968). Then, Eckblad (1968) classified 21 genera into Pyronemataceae and 49 genera by Korf (1973), one of the genera is Trichaleurina.

Identification using RAxML has a result that the specimen of BO 24420 is classified as $T$. javanica. This identification is supported by the specimen's specific morphology, such as the size and number of oil globules of ascospores. The bootstrap value is $81 \%$ in the $T$. javanica clade. The phylogenetic tree in Figure 2 also showed the separation among Bulgaria, Galiella, and Trichaleurina. This phylogenetic tree is monophyletic. Trichaleurina javanica has an anamorph culture, namely Kumanasamuha (Carbone et al., 2013). The genus is built 
and described by P.Rag. Rao \& D. Rao (Rao \& Rao, 1964). But the species name is not built yet. The anamorph is only similar morphologically with Kumanasamuha sundara but different by shorter conidiophores and fertile lateral branches, and smaller conidia (Carbone et al., 2013).

The goblet-shaped mushrooms such as Bulgaria, Galiella, and Trichaleurina are not popular to report the potency. Only Galiella has been reported for edible in Sarawak (Abdullah \& Rusea, 2009), identified as G. rufa, known as 'mata kerbau' (buffalo eyes) in local people. Other reports for other genera have not available yet for the edible category. Matias et al. (2016) successfully reported the angiogenic and anti-tumor potential of Trichaulerina mushroom. This potency is also supported for knowing of the secondary metabolite identification. Sogan et al. (2018) identified the secondary metabolite from $T$. celebica, which contains alkaloids, fatty acids, triterpenes, sterols, steroids, anthraquinones, anthrones, and steroids. Altogether, T. celebica has promising bioactivities which can be utilized in the nutraceutical or pharmacological industry

\section{References}

Abdullah, F. \& Rusea, G. (2009). Documentation of inherited knowledge on wild edible fungi from Malaysia. Blumea, 54, 35-38. https://doi.org/10.3767/000651909X475996

Boedijn, K. B. (1932). The genus Sarcosoma in Netherlands India. Bulletin du Jardin Botanique de Buitenzorg, 3e série, 12, 273-279.

Carbone, M. \& Agnello, C. (2015). Studies in Galiella (Ascomycota, Pezizales). III. The identity of Sarcosoma orientale and Wolfina papuana. Ascomycete.org., 7, 232-238.

Carbone, M., Yei-Zeng, W. \& Chun-Lin, H. (2013). Studies in Trichaleurina (Pezizales). Type studies of Trichaleurina polytricha and Urnula philippinarum. The status of Sarcosoma javanicum, Bulgaria celebica, and Trichaleurina tenuispora sp. nov., with notes on the anamorphic genus Kumanasamuha. Ascomycete.org., 5, 137-153.

Eckblad, F. E. (1968). The genera of the Operculate Discomycetes. A reevaluation of their taxonomy, phylogeny, and nomenclature. Nytt Magasin for Botanik, 15, 1-191.

Hansen, K. \& Pfister, D. H. (2006). Systematics of the Pezizomycetes - the operculate Discomycetes. Mycologia, 96, 1029-1040. https://doi.org/10.1080/15572536.2006.11832631

Index Fungorum. (2020). www.indexfungorum.org (Accessed April 12, 2020).

Kirk, P. M., Cannon, P. F., Minter, D. W. \& Stalpers, J. A. (2008). Dictionary of the Fungi (10 ${ }^{\text {th }}$ edition). CAB International.

Kottapalli, S., Krishna, H., Venumadhav, K., Nanibabu, B., Jamir, K., Ratnamma, B. K., Jena, R. \& Babarao, D. K. (2016). Preparation of herbarium specimen for plant identification and voucher number. Roxburghia, 6, 111-119.

Korf, R. P. (1973). Discomycetes and Tuberales. In: Ainsworth GC, Sparrow FK, Sussman AS, eds. The Fungi: an Advanced Treatise IV. p 249-319. Academic Press.

Matias, C., Maslang, J., Bungihan, M., Saludarez, M., Liday, D., Villanueva, H., Balonquita, M. \& Mariñas, M. (2016). Isolation of the Cytotoxic, Angiogenic, and Anti-tumor compounds from Trichaluerina celebica (Undergraduate Thesis). Saint Mary's University.

Mycobank. (2020). Trichaleurina javanica. http://www.mycobank.org/name/Trichaleurina\%20javanica\&Lang=Eng (Accessed April 12, 2020).

Noverita, Nabilah, Siti, F.Y. \& Yudistari. (2018). Macrofungi on Saktu Island Kepulauan Seribu Jakarta Utara and their potential. Jurnal Mikologi Indonesia, 2, 16-29. https://doi.org/10.46638/jmi.v2i1.38 
Patel, R. S., Vasava, A. M. \& Rajput, K. S. (2018). Distribution of Trichaleurina javanica (Rehm) M. Carbone, Agnello \& P. Alvarado (Chorioactidaceae) in India. Plant Biosystem - An International Journal Dealing with All Aspects of Plant Biology, 1-4. https://doi.org/10.1080/11263504.2018.1461704

Perry, B. A., Hansen, K. \& Pfister, D. H. (2007). A phylogenetic overview of the family Pyronemataceae (Ascomycota, Pezizales). Mycological Research, 3, 549-571. https://doi.org/10.1016/j.mycres.2007.03.014

Rao, P. R. \& Rao, D. (1964). Kumanasamuha a new genus of Dematiaceae. Mycopathologia, 22, 330-334. https://doi.org/10.1007/BF02049066

Rehm, H. (1903). Die Discomyceten-Gattung Aleurina Sacc. Annales Mycologici, 1, 514-516.

Rehm, H. (1914). Ascomycetes Philippinenses VI -Communicati a clar. C. F. Baker. Leaflets of Philippine Botany, 6, 2257-2281.

Rifai, M. A. (1968). The Australasian Pezizales in the Herbarium of the Royal Botanic Gardens Kew. Verhandelingen Koninklijke Nederlandse Akademie van Wetenschappen, Afd Natuurk, Tweede Sect, 57, 1-295.

Sogan, M. M., Maslang, J. A. L. \& Dulay, R. M. R. (2018). Myco-chemicals and teratogenic activity of wild mushroom Trichaleurina celebica from Mt. Palali, Quezon, Nueva Vizcaya, Luzon Island, Philippines. The CLSU International Journal of Science \& Technology, 2, 17-23. https://doi.org/10.22137/ijst.2018.v3n2.03

Stamatakis, A. (2014). RAxML Version 8: A tool for Phylogenetic Analysis and PostAnalysis of Large Phylogenies. Bioinformatics. http://bioinformatics.oxfordjournals.org/ content/early/2014/01/21/ bioinformatics.btu033.abstract. 